\title{
Service innovation roadmaps and responsible entities learning
}

\author{
Jim Spohrer ${ }^{1, *}$ \\ ${ }^{1}$ Director, Cognitive Opentech Group (COG), IBM Research Almaden, USA \\ Co-founder of the International Society of Service Innovations Professionals http://issip.org/
}

\begin{abstract}
Service-Dominant Logic (S-D Logic) and service science provide a way for innovators and learners to look at the world differently and thereby improve quality-of-life for people over time. The continued development of service science as an emerging transdiscipline will depend on developing better measurements and tools for understanding the past and future identities, reputations, values, goals, and strategies of entities interacting to achieve outcomes. For example, Service Innovation Roadmaps (SIRs) can be thought of as an attempt to make explicit the "learning investment strategy" of responsible entities (people, businesses, regional governments) to change and become "better future version of themselves" in terms of value co-creating service interactions. In short, SIRs can help with the challenge of upskilling people in an age of accelerating technology and policy changes. All service systems, as responsible entities learning, invest in three types of activities, herein termed RunTransform-Innovate activities. This short paper provides context for a research direction to develop further the notions of SIRs and embrace complexity economics as a tool for advancing service science.
\end{abstract}

\section{Introduction}

To advance service science, the Cambridge SSME report urged stakeholders to create Service Innovation Roadmaps (SIRs) [1]. Over a decade later an even bigger opportunity exists to advance service innovation during the pandemic as work is disrupted and being transformed. In 2021, the World Economic Forum (WEF) identified a 6 trillion Euro "upskilling opportunity" for workers enabling higher value jobs and a shared prosperity [2]. Service-Dominant Logic (S-D Logic) and service science provide a way to look at the world differently from traditional Goods-Dominant Logic (G-D Logic); abstractly this involves seeing the world of socio-technical systems in terms of entities (resource integrators, service systems), interactions (value propositions, institutions), and outcomes (ISPAR) [3]. However, how can this translate into practice for innovators and learners? Specifically, what are Service Innovation Roadmaps (SIRs) and are they a practical tool for learners?

How do SIRs relate to upskilling? SIRs can help responsible (service system) entities invest more mindfully in learning and change [4]. March [5] explains learning as a fundamental investment decision that organizations make in exploration and exploitation activities. Building on this prior work, March's two-option learning investment framework, Spohrer

\footnotetext{
*e-mail: spohrer@us.ibm.com
} 
and Maglio[6] and [7], explain learning of service system entities in terms of a three-option learning investment framework- called Run-Transform-Innovate (R-T-I). A version of R-TI was used by IBM CIO office in the late 1990's and early 2000's to grow IBM's service business [8], [9]. In practice, SIRs are a modified version of the business model canvas that responsible entities can use to become more explicit about their R-T-I investment in learning and upskilling. Variations of the business model canvas have been studied from a service logic perspective [10]. Individuals, businesses, regional universities and governments, and nations can all create SIRs to help them better succeed through service innovation, while simultaneously upskilling towards a deeper understanding of service science. Consistent with a positive, growth mindset, we see the practice of creating and revising SIRs as one of the very best practical ways to put service science in action for learners, innovators, and leaders.

\section{Looking Back}

Looking back, forty years ago it was 1981; the internet and software industry were still largely in their infancy. While IBM mainframes dominated the enterprise, clearly the personal computer in the US and expert systems with Japan's 5th generation super-computing initiative were gaining more attention. A decade later, the world-wide-web, internet browsers and mobile phones were cutting edge and Finland's Nokia was preferred by many, and yet a Y2K software menace loomed on the horizon. Entering the 2000's the internet bubble gave birth to future e-commerce (Amazon) and search and advertising platform giants (Google), while also providing a lesson in investment bubbles and venture capitalists portfolio approach on technology trends foresight. Gaming (Nvidia GPUs), music (Apple's iPod), and social networks (Facebook, Linkedin, Twitter) were in their infancy, and then with smartphones (Apple, Samsung) the democratization of access to information, real and fake, took off like a rocket. It was also becoming clear that batteries needed to improve greatly for smartphones and for electric vehicles (Tesla), amid increased concerns about climate change. In the 2011, first with IBM's Watson Jeopardy then with renewed academic and then industry progress in open-source deep learning and large open datasets, suddenly there was greatly renewed interest in Artificial Intelligence (AI), and also deep concerns about Trusted AI that was fair, explainable, and robust against adversarial attacks. In 2020, the pandemic struck, accelerating the digital transformation of business and society, and Zoom became a household word.

Looking back, smartphones have become as essential as clothing; always near us. The internet, personal computer, and smartphones are the advancements that enable essential service interactions during the pandemic - ordering and receiving physical goods that arrive in boxes at the doorway, coordinating daily interactions both mundane and complex business deals. Where would we be without our smartphones? Smartphones required advancements in human knowledge on a range of topics, including the internet, miniaturization, rare earth elements, human-computer interactions, batteries, low energy hardware and software integration, and much more.

\section{Looking forward}

Looking forward, constant upskilling of people of all ages will be essential - a positive growth mindset and entrepreneurial mindset will become important to keep up with the pace of accelerating change. In a decade or two vehicles will drive themselves, no water shortages because cities will recycle water, manufacturing will be local again because of robotics and 3D printing, no energy shortage because of advances in artificial leaf, geothermal, and miniature nuclear, construction technology will be automated - already China's Broad Group can 
build 30-story building in 15 days, retail goes social, finance goes crowd funded, all robotic surgery and 3D printed organs, education will look like a team sport where even young children work on real-world innovation projects, and while it may be hard to believe - because of a better understanding of decision-making and game-theory, and how to invest wisely in the weakest-links and not simply reward the strongest links in society, even government works better! For more on the future of AI see [11].

Looking forward, forty years ahead, our cognitive mediators will provide a form of virtual immortality for our digital twins. As smartphones apps "grow up," hundreds of apps will become our digital workers - across healthcare, finance, entertainment, communication, collaboration - apps will get speech interfaces, human-like memories, and fluent social interaction capabilities that allow them to fill roles in "the business of me and you"; first apps as tools, then assistants, collaborators, coaches, and eventually mediators that we trust to negotiate and make certain decisions on our behalf, and in some ways knowing us better than we know ourselves - will appear, as digital twin technologies advance. Today, who knows you best? This will change in forty years for tasks that can be predicted. The best way to predict the future will be to inspire the next generation to build it better; all responsible entities, people, businesses, universities, governments, will have cognitive mediators (digital twins) that are competing for collaborators to make "better future versions of themselves". We, in the service science community, work to understand the logic of human destiny, better value cocreation and win-win games, and also how entities become not only smarter service systems (with digital twins), but wiser service systems (with values, conscience, and imagination) on a multi-generational journey towards better future versions of themselves balancing rewarding strongest and weakest links, capabilities and constraints, rights and responsibilities. Wiser service systems will likely value highly the hard work of periodically rebuilding from scratch to explore more possibilities, while sustaining the zone of proximal development that balances challenge (anxiety) and routine (boredom) - what James March called exploration and exploitation of knowledge by learning entities.

\section{Concluding Remarks: Challenges, Benefits, Risks, and Research Directions}

The big challenges of advancing AI towards cognitive mediators (digital twins of people and more) are: (1) deskilling (people becoming overly reliant on their AI to make life easier which is a kind of over investing in the routine) and (2) malicious uses (people seeking to advance their goals in a way that harms others - too many investing in win-lose interactions). Nevertheless, the benefits of cognitive mediators could be better access to expertise and more productive collaborations. Value co-creation with capability co-elevation requires us to be practical and think more about upskilling.

The big risk is not investing enough in upskilling consciously (mindfully). Responsible entities (people, businesses, universities, governments) should consider the challenges and benefits of maintaining Service Innovation Roadmaps (SIRs) which are a kind of business model canvas for their investment in their own mindful upskilling. Run-TransformInnovation upskilling is about (1) Run - what to invest in doing routine activities (limited learning, primarily from simple expectation violations that need to be repaired), (2) Transform - what to invest in copying best practices from others (social learning), and (3) Innovate - what to invest in exploring and creating new knowledge and activities more adapted to future opportunities (innovation learning). Most entities make these investment decisions unconsciously - which limits individual and collective learning. When people have cognitive mediators (digital twins of themselves) there is the opportunity to invest even more in up- 
skilling. However, the investments have to be made wisely; ultimately, as judged by future generations which presents a dilemma.

What research directions does this line of reasoning suggest? If someday all responsible entities have digital twins, and all maintain Service Innovation Roadmaps (SIRs) to shape their investments in upskilling and learning, then the stage will be set to use the tools of complexity economics [12]. Simulating millions of "runs" of responsible entities adapting their strategies to the challenges and opportunities at hand will not suggest a single possible future, but multiple possible futures, providing a new tool for service scientists. This type of tool could help responsible entities learn, and more wisely achieve value co-creation with capability co-elevation.

\section{Acknowledgements}

Many thanks to Michel P. Leonard for the invitation to provide a presentation about this topic at IESS 2.1 on March 25, 2021, and the opportunity to create this extended abstract to accompany the presentation [13].

\section{References}

[1] IfM and IBM, Succeeding through Service Innovation: A Service Perspective for Education, Research, Business and Government, https://www.ifm.eng.cam.ac.uk/uploads/Resources/Reports/080428cambridge_ssme_ whitepaper.pdf (Institute for Manufacturing, Cambridge, MA., 2008)

[2] WEF and PwC, Upskilling for shared prosperity. World Economic Forum, Geneva, Switzerland, with PricewaterhouseCoopers (PwC) (2021)

[3] P.P. Maglio, S.L. Vargo, N. Caswell, J. Spohrer, The service system is the basic abstraction of service science, Information Systems and e-business Management 7(4), 395-406 (2009)

[4] J. Spohrer, Service Science and Service Innovation,Blog post, Available online at http://service-science.info/archives/5443 (2021)

[5] J.G. March, Exploration and exploitation in organizational learning, Organization Science 2(1), 71-87 (1991)

[6] J. Spohrer, P.P. Maglio, Service science: Toward a smarter planet, in Introduction Service Engineering, G. Salvendy, W. Karwowski (Eds.) (Wiley, New York, 2010) 3-30

[7] J. Spohrer, P.P. Maglio, Toward a Science of Service Systems, in Handbook of Service Science, P.P. Maglio, C.A. Kieliszewski, J.C. Spohrer (Eds.) (Springer US, Boston, MA, 2010) 157-194

[8] L.S. Sanford, Let Go to Grow: Escaping the Commodity Trap (Prentice Hall, 2004)

[9] J. Spohrer, IBM's service journey: A summary sketch, Industrial Marketing Management 60, 167-72 (2017)

[10] J. Ojasalo, K. Ojasalo, Service Logic Business Model Canvas, Journal of Research in Marketing and Entrepreneurship 20(1), 70-98 (2018)

[11] J. Spohrer, The Future of AI and Business Value: A Service Science Perspective, Talk to Norway Business School, March 9, Available online at https://www.youtube.com/watch?v=x4GS5weai8k (2021)

[12] W.B. Arthur, Foundations of complexity economics, Nat Rev Phys 3, 136-145 (2021)

[13] J. Spohrer, Service Innovation Roadmaps and Responsible Entities Learning, IESS 2.1 Presentation. March 25, Available online at https://www.slideshare.net/spohrer/20210325jim-spohrer-sir-rel-futureai-v10-copy (2021) 